\title{
BEST-SELLERS DA CULTURA DE MASSA E FORMAÇÃO DE LEITORES: SUBJETIVIDADES EM CONTEXTO
}

\section{BEST SELLERS OF MASS CULTURE AND FORMATION OF READERS: SUBJECTIVITIES IN CONTEXT}

\author{
Luzimar Silva de Lima ${ }^{1}$ \\ Shirlei Marly Alves ${ }^{2}$
}

Resumo: Este artigo, recorte da dissertação de Lima (2019), analisa a contribuição que os bestsellers da cultura de massa apresentam para a formação de leitores na escola. Para tanto, realizou-se uma pesquisa de campo em três escolas públicas municipais de $9^{\circ}$ ano do ensino fundamental da cidade de Buriti dos Lopes-PI. O suporte teórico que embasa a pesquisa provém de autores como: Compagnon (1996), Todorov (2009), Barthes (1977), Bloom (2001). A análise dos dados revelou o gosto e o apreço que os estudantes pesquisados tem pelos bestsellers da cultura de massa, compreendendo-os como leituras fruitivas de hábito consolidado.

Palavras-chave: Literatura; Best-sellers; Formação de leitores; Subjetividades

Abstract: This article analyses a sample corpus from Lima's dissertation (2019). It analyzes the contribution that the best sellers of mass culture present to formation of readers in the school. Therefore, it was done a field research in three municipal public schools of 9th grade in the basic education in Buriti dos Lopes-PI. The theoretical support that bases this research are authors as: Compagnon (1996), Todorov (2009), Barthes (1977), Bloom (2001). The analyze of the data revealed pleasure and appreciation that these students have about best sellers of mass culture, including them as fruitive readings, as consolidated habit.

Keywords: Literature; Best sellers; Readers Formation; Subjectivities.

\section{Introdução}

O ensino de literatura tem sido alvo de muitas pesquisas que enfocam as metodologias usadas para levar o leitor ao contato com o cânone e, sobretudo, a recepção dessas obras na escola, espaço inicial de formação de leitores e de acesso às obras literárias. Algumas críticas têm sido feitas ao processo de escolarização da literatura (SOARES, 2011), sobretudo, por provocar uma certa descaracterização da relação leitor-obra, visto que esta deixa de ser recepcionada como objeto estético, pois passa a ser tratada como uma atividade de identificação de informações e outros elementos. Infere-se, assim, que a abordagem da literatura na escola

\footnotetext{
${ }^{1}$ Mestre em Língua Portuguesa pelo Mestrado Profissional em Letras-PROFLETRAS - Universidade Estadual do Piauí. Orcid: https://orcid.org/0000-0002-0919-6105. E-mail: luzilii@htomail.com

${ }^{2}$ Doutora em Letras. Professora do Mestrado Profissional em Letras-PROFLETRAS - Universidade Estadual do Piauí. Orcid: http://orcid.org/0000-0001-5305-1272
} 
carece de olhares para a efetivação do seu papel humanizador, direcionado às subjetividades dos sujeitos leitores a partir da fruição estética, função essencial da literatura (COSSON, 2015).

Como consequência, tem-se atestado certo distanciamento dos adolescentes e jovens do universo da literatura canônica, enquanto, por outro lado, para muitos desses leitores, os bestsellers da cultura de massa apresentam-se como obras de leitura frequentes, às quais atribuem as mesmas funções que a literatura ${ }^{3}$ oferece, isto é, são lidos por motivações próprias e irrompem uma natureza fruitiva que arrebanha centenas e até milhares de leitores para esse universo.

Ora, se os best-sellers da cultura de massa fazem tanto sucesso entre esses leitores, algum proveito há de se tirar dessas leituras em contexto pedagógico, inclusive, acreditamos que podem servir como elemento essencial da inserção do cânone literário nas escolas. Assim, os alunos se sentirão valorizados em suas preferências, e suas expectativas de leitura podem ser alargadas com a apresentação de obras desafiadoras - aquelas já consagradas pelo cânone e que, sem dúvida, permanecem fundamentais a uma educação humanística que valoriza o estético bem como o caráter crítico sobre as realidades que marcam o ser humano.

A esse respeito, desenvolvemos um trabalho que busca compreender mais de perto a relação entre os jovens leitores e os best-sellers da cultura de massa. Para tanto, realizamos uma pesquisa de campo de cunho qualitativo, no intento de analisar as subjetividades dos leitores, alunos de três escolas públicas municipais da zona urbana do município de Buriti dos LopesPI. Os dados foram obtidos através de uma entrevista realizada com 30 participantes, os quais compuseram uma amostra de 10 alunos de cada turma. As escolas receberam um código, sendo nomeadas como E1, E2 e E3. Os alunos também receberam código de identificação chamados A1, A2, A3, e assim sucessivamente.

Com a pesquisa foi possível perceber um apreço pela leitura dos best-sellers da cultura de massa pelos alunos, uma identificação que corresponde às suas próprias expectativas de vida, pois tais obras marcam uma representação de seus propósitos particulares de vida: amores, paixões, decepções, desilusões, aventuras, romances, mistérios entre outros. Por essa razão, percebe-se que há necessidade de essas leituras serem valorizadas pela escola, onde podem servir também como motivação para a inserção da literatura canônica, mas sem descaracterizálas.

\footnotetext{
${ }^{3}$ Referimo-nos à literatura canônica, visto que, para grande parte da crítica, os best-sellers da cultura de massa não são considerados obras literárias.
} 


\section{0 cânone e a escola: implicações metodológicas}

Vemos que a literatura deve despertar em seus leitores um sentimento de prazer, gratuidade e fruição estética, permitidos pela interação com o texto lido. Essa arte tem caráter humanizador e, por essa razão deve, especialmente no espaço escolar, cumprir tais funções. No entanto, percebe-se na escola uma certa recusa pelas obras canônicas em vista de que muitas metodologias adotadas nesses espaços são pouco motivadoras e suprimem da literatura suas funções intrínsecas. Em grande parte das vezes, ler a obra desemboca apenas no preenchimento de fichas de leituras ou alguma produção de texto, vistas pelos estudantes como uma obrigação ou expediente para aquisição de nota.

A escassez das práticas de leitura literária na escola foi alvo de discussão por parte de muitos estudiosos, dentre os quais destacamos Todorov (2009) e suas contribuições acerca do ensino da literatura na escola e a condução que tem tomado nesse espaço. Segundo o autor, o perigo não está na escassez de poetas contumazes ou ficcionistas, mas na forma como a literatura tem sido oferecida aos jovens desde a escola primária até a faculdade, ou seja, a escolarização da literatura parece ser o grande perigo de sua inexistência. O perigo diz respeito ao fato de que o estudante não entra em contato com a literatura por meio dos textos literários, mas com alguma espécie de crítica, de teoria ou de história literária, o que revela muito mais uma matéria do que a viabilização de conhecimento do mundo, do próprio ser humano e suas paixões.

O cânone literário ocupa sem dúvida a centralidade do ensino de literatura nas escolas e academias, porém a forma como são apresentadas as obras carece de uma atenção maior, sobretudo quando se trata de leitores iniciantes. Essa literatura caracteriza-se com uma linguagem mais difícil, figurada, apresentando muitas vezes uma distância estética que desafia os leitores. Esses fatores somados podem estar nas bases da recusa do cânone pelos jovens leitores.

Numa perspectiva histórica, Faria (2003) esclarece que o estudo da literatura no Brasil data do século XIX, quando era abordado na perspectiva da crítica e da história literárias. A primazia do cânone predominava como essência de ensino.

Na tradição da história da literatura, que se iniciava então, ocorria aqui o mesmo que na Europa: a abordagem da literatura, ajustada ao ideal de objetividade histórica, descreve o passado restringindo-se ao cânone das obras e autores consagrados pela tradição, excluindo textos divergentes de um determinado modelo de literatura. Tais considerações fazem-nos pensar sobre a constituição do cânone escolar e a razão 
porque algumas obras ficam fora da lista de obras tradicionalmente apresentadas no panorama histórico. (FARIA, 2009, p. 3).

Observa-se, pois, que o ensino de literatura na escola insere-se num terreno de relações estreitas e pouco pacíficas, parecendo manter-se na escola apenas por força de normatizações, como tradição e exigência curricular. Além disso, a função educativa que essa literatura exerce na escola limita-se a uma concepção do ato de ler com o único propósito de promover a formação cultural do leitor. Quanto a isso, Freire afirma que:

\begin{abstract}
Já se pensou que a literatura teria a função de educar e elevar os alunos, ajudando a formar o seu caráter, advindo também daí a noção dos autores clássicos, ou seja, aqueles cujos textos eram dignos de ser lidos em classe. Desse conceito de clássicos, mais tarde ampliado para significar que esses autores eram intocáveis e sua leitura obrigatória para os leitores cultos, passa-se ao conceito de cânone, que engloba aqueles livros tornados únicos, quase sagrados - e, vale dizer, em geral pouco lidos. Não discutirei aqui a tentativa de tornar "natural" o apreço por esses livros, pois sabemos que o fato de um livro ser considerado clássico ou um autor ser elevado à categoria de canônico depende muito de cada época. (FREIRE, 2010, p. 195)
\end{abstract}

As palavras de Freire enfatizam a realidade das escolas e academias, onde, se o percurso formativo desses estudantes não apresentar um repertório significativo de leituras do cânone, um problema grave no ensino de literatura deve estar acontecendo. Desse modo, a importância dada a essas obras faz cegar quaisquer outras formas de literatura, fazendo surgir a clássica divisão da crítica sobre os livros da literatura - o cânone - e os não literários, como por exemplo, os advindos da cultura de massa.

Bloom (2001) explica que:

ORIGINALMENTE, O CÂNONE significava a escolha de livros em nossas instituições de ensino, e apesar da recente política de multiculturalismo, a verdadeira questão do cânone continua sendo: Que tentará ler o indivíduo que ainda deseja ler, tão tarde na história? Os setenta anos bíblicos já não bastam para ler mais que uma seleção dos grandes escritores do que se pode chamar de tradição ocidental, quanto mais de todas as tradições do mundo. Quem lê tem de escolher, pois não há literalmente, tempo suficiente para ler tudo, mesmo que não se faça mais nada além disso. (BLOOM, 2001, p. 21)

Conforme Cosson (2015), o cânone literário, também denominado clássico ou obraprima, é constituído por um conjunto de autores e obras que são considerados representativos para uma determinada nação ou idioma. O cânone literário compreende os valores universais e socialmente instituídos, sendo que essa classificação depende não somente da crítica, mas também de outras instituições, dentre as quais a escola, considerada a mais representativa de legitimação. 
A sacralidade do cânone precisa ser repensada, no sentido de que o mundo da leitura apresenta um contexto amplo de leituras possíveis, e os alunos estão imersos nele, o que permite pensar a valorização das leituras já trazidas pelos estudantes para o espaço da escola e partir delas inserir outras de natureza mais complexas. Não valorizar as leituras que os alunos fazem por iniciativa própria, fora do que orientam os currículos escolares, pode estar na base da recusa ou do desprestígio das obras que, tradicionalmente, estão nos espaços escolares - o cânone, muitas vezes, tomado como imposição por parte do educando.

Por essa razão, acreditamos que as metodologias direcionadas à literatura precisam priorizar essas preferências, partindo do conhecido pelos alunos, rumo ao que ainda é desconhecido por eles, a leitura do cânone, trabalhando as similaridades que apresenta com as obras mais populares. Para tanto, é necessário um diagnóstico que verifique que repertório de leitura os estudantes já levam à escola.

\section{Best-sellers da cultura de massa e formação de leitores}

Verificamos a presença dos best-sellers da cultura de massa no universo de leitura dos estudantes, no entanto grande parte dos professores recusam essas leituras por acreditarem que nada acrescentam à formação leitora dos alunos. São, assim, tachadas de leituras alienadoras, que seguem uma receita cujo fim é agradar ao público e conseguir consumidores, sem nenhuma distância estética que os desafie. Cumpre ressaltar que uma ala de críticos pensa dessa maneira, o que favorece o desprestígio dessa literatura nas escolas e academias.

Mas o que é um best-seller da cultura de massa?

Lima (2015) afirma que o livro denominado best-seller é fruto da cultura de massa, que começou a se consolidar no século XIX e se tornou um gênero à parte, menosprezado pela elite e pelas escolas, porém de grande receptividade popular.

Rossato (1994) explica o best-seller referindo-se aos franceses, que deram o nome genérico de paraliteratura (paralitératture) ao que nós convencionamos chamar de literatura da massa, ou best-seller, que vende milhões de exemplares e enriquece seus autores e editores com textos considerados "dirigíveis" e "envolventes", próprios para o entretenimento dos leitores ávidos por uma história.

Os conceitos estabelecidos pelos estudiosos permitem considerar que essa literatura não é bem-vista pela crítica e por grande parte das escolas, mas apenas torcer o nariz para essa realidade é desconsiderar as expectativas e práticas de leitura de muitos leitores. Ademais, não 
há leitura que não traga conhecimento, por mínimo que ele seja. Quando se fecha os olhos para essa realidade, corre-se o risco de impor leituras, a exemplo do que acontece com o cânone, e sofrer recusa, descaracterizando as funções que deve apresentar essa arte fruitiva. Sobre isso, Dumont esclarece que:

\begin{abstract}
Alguns combatem ardorosamente a literatura de massa, taxando-a de alienadora e culpando-a de não iniciar o leitor a observar e questionar os problemas que o circundam, trazendo, pelo contrário, a acomodação. Em contrapartida, existe uma ala mais moderada, que, mesmo reconhecendo que essa literatura não possui os padrões desejáveis da literatura como arte informativa e enriquecedora, sua leitura permite, através da ótica de cada leitor, de seu contexto, que algo se aproveite, por ínfimo que seja, vindo então a acrescentar informação a sua vivência [...] quanto mais ler, mais informações o sujeito possuirá para discernir em situações em que se lhe presente no futuro. (DUMONT, 2000, p. 167)
\end{abstract}

Os defensores atestam uma validade que de fato existe e deve ser percebida pela escola, visto que os contextos atuais revelam esses leitores a partir do constante sucesso dessas obras, permitido pela acessibilidade com que se dispõem na sociedade. O consumo acelerado faz o mercado editorial investir sempre mais, e a receptividade popular permite a esse tipo de mercado seguir padrões ou receitas de uma obra, constituindo um grande número de exemplares vendidos e a produção de obras em séries, como as sagas, por exemplo. As subjetividades dos leitores mudaram, novos horizontes surgiram.

A escola precisa estar aberta às questões apresentadas, também pelo fato de que muitos alunos podem dizer que leem literatura quando estão diante dos best-sellers. O ideal seria, a partir deles, discutir o valor literário que apresentam. Que no contexto da aula se discuta: o que é literatura?

Temos visto um mercado editorial forte e as estratégias de marketing direcionados ao público consumidor de obras dessa categoria, porém o fato de um livro ser o mais vendido não significa que apresente obrigatoriamente valor literário pelo sucesso de vendas e pela multidão de leitores que faz. Considera-se também que negá-las é ir contra as vivências leitoras dos alunos. Nesses últimos anos, a saga Harry Potter conquistou uma legião de leitores e expectadores no cinema. Essa é uma realidade crescente que envolve grande parte dos jovens.

Como administrar essas leituras e ao mesmo tempo contemplar os clássicos? Essa é uma questão que, hoje, deve fazer parte das reflexões acerca do que acontece na sala de aula quando falamos no ensino de literatura. Riolfi et al. consideram que: 


\begin{abstract}
Poderíamos nos contrapor à presença dos chamados Best-sellers - e os similares - nas aulas de Língua Portuguesa com base em uma oposição simples: se deles já se ocupam o marketing editorial, a mídia, as livrarias, a internet (eles são sempre os primeiros à mostra), para que o professor precisa se ocupar dele também? De fato, essa seria uma razão plausível, mas simplesmente ignorá-los significaria não levar à sala de aula a discussão sobre as razões, sejam textuais, sejam históricas de esses livros não permitirem o acesso ao que é específico do literário. Seria necessário, em um estágio avançado de leitura em sala de aula, discuti-los, para demonstrar, por meio de análises, como as estratégias discursivas se repetem nesse tipo de obra. (RIOLFI et al., 2014, p. 79)
\end{abstract}

Os autores apresentam respostas bem contundentes de que essas leituras e o trabalho com elas em sala de aula devem ser evitados, endossando a ideia de que não são leituras válidas. A proposta é, pois, que o trabalho de contemplação de best-sellers em sala de aula sirva apenas para desqualificá-los no confronto com as obras que de fato são literárias, os clássicos.

Evidencia-se na proposta desses autores apresentam uma visão muito radical e redutora quando orientam para desqualificar o acervo que, para os jovens leitores, é de muito valor, como se a ênfase devesse estar em mostrar aos alunos que não sabem fazer escolhas e nem fazer as devidas apreciações, visto que aquilo que leem apresenta apenas características apenas negativas. Essa é uma ação frustrante para aqueles estudantes que de fato são leitores efetivos de best-sellers da cultura de massa.

De nossa parte, propomos que a abordagem da leitura na escola pode e deve partir daquilo que os alunos já conhecem, ou seja, das leituras que eles já fazem, num percurso que vai do conhecido ao desconhecido, em um processo de continuidade e valorização que chegue ao cânone literário. Advertimos, entretanto, não se trata simplesmente de usar os best-sellers como pretexto para a análise dos clássicos, visto que possuem significado para os alunos e contemplam muitos aspectos que merecem ser analisados em sala de aula. A exemplo citamos: temas, enredo, personagens, conflitos sociais, aspectos históricos, culturais, os quais podem suscitar conversas, debates entre os leitores, os quais podem ser, inclusive, conduzidos à apreciação do estilo e de outros elementos da linguagem típicos dessas obras.

O trabalho com literatura canônica, na escola, sem dúvida, principalmente, nos anos mais avançados do Ensino Médio, deve ser prioridade, mas não implica em desqualificar as leituras da literatura de cultura de massa que são parte da vivência dos alunos. É necessário mostrar que elas têm o seu valor, mas que a ampliação do universo de leituras é necessária. Podemos traçar comparativos entre uma obra literária e não literária, analisá-las e mostrar ao aluno que ambas apresentam características em comum. Trabalhar com similaridades é importante porque insere, de maneira prazerosa, o aluno em leituras mais complexas, 
favorecendo a inserção de leituras outras, principalmente os clássicos. É possível tirar muito proveito dessas leituras com a abordagem correta e com um percurso metodológico favorável a isso.

Riolfi et al. (2014) ainda tecem severas críticas às bibliotecas de acervo governamental e à qualidade desses livros, afirmando que, no geral, é dessa política que tal acervo é formado. Segundo os autores, essas bibliotecas apresentam desvantagens, e uma das consequências é que normalmente, nas aulas de leitura, os professores utilizam os livros sem que a pergunta: "o que é literatura?" seja sequer cogitada, ou seja, não se transforma em questionamento, em discussão nas aulas de leitura. Essa questão é respondida no sentido de que se consideram todos os livros que constam na biblioteca como literatura, o que contribui, segundo os autores, para desnortear as práticas escolares.

Reiteramos que apenas pensar nos aspectos negativos e ter os best-sellers como ameaça ao texto literário são fatores que não resolverão o impasse, visto que os problemas do ensino de literatura não serão resolvidos se os best-sellers forem proibidos ou deixarem de fazer parte da escola. Podemos excluí-los das bibliotecas, mas os alunos continuarão a lê-los, ou seja, negálos na escola não impedirá que sejam lidos, tampouco de fazerem parte das leituras preferidas dos adolescentes. Ações articuladas e medidas devem ser pensadas, no sentido de não contrariar ou impor leituras que, inicialmente, serão negadas pelos alunos, afinal eles já fazem por iniciativa própria suas leituras de gosto pessoal. É urgente, pois, que a abordagem pedagógica do texto literário seja repensada.

\section{Literatura, best-sellers e subjetividades: o prazer do texto}

Os participantes da pesquisa trazem uma visão de texto/obra como experiência de prazer, visto que se revelam conquistados para a leitura dos best-sellers da cultura de massa, no sentido de que "Texto de prazer: aquele que contenta, enche, dá euforia; aquele que vem da cultura, não rompe com ela, está ligado a uma prática confortável da leitura." (BARTHES, 1987, p. 21). No entanto, para esse autor, há a necessidade de também ser efetivada a fruição que é permitida por textos desafiadores, entre os quais incluímos o cânone, no seguinte sentido: 
Compreende-se, pois, que a fruição estética é uma necessidade, e o efeito estético só é alcançado quando, de alguma forma, o leitor sente-se tocado, desafiado, frustrado por aquilo que lê. Quando essa mesma fruição ocorre, há um sentimento de pertencimento ao texto ainda que, às vezes, estranho ao leitor. Por essa razão, deve-se considerar que, para além dos muros da escola, os alunos também leem, indicam suas leituras favoritas e compartilham experiências. Isso corrobora a necessidade de práticas valorativas dessas leituras de prazer para direcioná-los às leituras de fruição, conforme expressa Barthes.

Foi com o intento de compreender as relações entre leitores e best-sellers que desenvolvemos uma pesquisa de campo com o objetivo de analisar aspectos da subjetividade dos estudantes de três turmas de $9^{\circ}$ ano do ensino fundamental de escolas públicas municipais da zona urbana de Buriti dos Lopes - PI. A pesquisa foi de cunho qualitativo, visto que o enfoque foi para a compreensão das relações desses leitores com os best-sellers da cultura de massa. Para tanto, responderam a uma entrevista a fim de verificar os aspectos citados. As escolas foram nomeadas com um código, sendo abordadas como E1, E2 e E3. Os alunos também receberam código de nomeação em face da privacidade de suas identidades, sendo nomeados como A1, A2, A3, A4, A5, A6, A7, A8, A9 e A10.

Nesse sentido, pôde-se perceber de perto como os alunos compreendem a leitura dos best-sellers da cultura de massa, como também a vivacidade que as obras têm hoje nas escolas, assim, mediante tal compreensão, é possível propor alternativas que valorizem essas leituras em busca da formação do leitor, não apenas um mero leitor, mas que saiba aproveitar suas leituras e agir criticamente sobre elas.

A esse respeito elegemos para organizar a pesquisa as seguintes categorias:

- Categoria 01 - Motivação ou influência na escolha do livro

- Categoria 02 - Relação de best-sellers conforme interesses de leitura

- Categoria 03 - Concepção de obra literária

\subsection{Implicações subjetivas na leitura de best-sellers: discutindo os resultados da pesquisa}

Os dados citados a seguir correspondem às práticas subjetivas que elevam os best-sellers da cultura de massa, para esses leitores, como literatura, não veem o desprestígio que essa literatura tem para grande parte da crítica. Destacam que os fatores do gosto, prazer e fruição são preponderantes para a leitura dessas obras. 
Procederemos a análise dos dados colhidos com a entrevista com base nas categorias já apresentadas.

Motivações para a leitura de best-sellers

Perguntados a respeito das motivações para leitura dos best-sellers, os alunos deram as respostas transcritas no quadro 1 :

Quadro 01- Motivações para a leitura de best-sellers em E1

\begin{tabular}{|c|l|}
\hline $\begin{array}{c}\text { Alunos da } \\
\text { E1 }\end{array}$ & \multicolumn{1}{c|}{ Motivações para a leitura dos best-sellers } \\
\hline A7 e A8 & $\begin{array}{l}\text { Leem best-sellers porque ouvem comentários sobre o romance quando os } \\
\text { amigos dizem ser bom. }\end{array}$ \\
\hline A1 & "A curiosidade de saber o enredo da história." \\
\hline A2 & "Leio para conhecer a história." \\
\hline A3 & "A curiosidade, histórias de magia...." \\
\hline A4 & O título e indicações. \\
\hline A5 & A curiosidade. \\
\hline A6 & "A curiosidade e indicações de uma prima." \\
\hline A9 & "Por achar bom, leio o início e se for bom leio todo se não pego outro." \\
\hline A11 & "Costumo ler por indicação de amigos." \\
\hline
\end{tabular}

Fonte: A pesquisa

Os participantes de E2 revelaram o que consta no quadro 2.

Quadro 2 - Motivações para a leitura de best-sellers em E2

\begin{tabular}{|c|l|}
\hline Alunos da E2 & \multicolumn{1}{c|}{ Motivações para a leitura de best-seller } \\
\hline A1 & $\begin{array}{l}\text { "Assisti a filmes e achei a história muito bonita... é interessante por trazer } \\
\text { aspectos da realidade." }\end{array}$ \\
\hline A3 & "Primeiro leio o resumo, depois por curiosidade leio a história." \\
\hline A5 & "É porque são legais." \\
\hline A6 & $\begin{array}{l}\text { "Leio porque gosto, por incentivo da minha mãe. Tem coisas próximas da } \\
\text { realidade." }\end{array}$ \\
\hline A7 & $\begin{array}{l}\text { "Acho que são interessantes. São personagens jovens mais próximos da } \\
\text { nossa realidade." }\end{array}$ \\
\hline A8 & $\begin{array}{l}\text { "Eu gosto de ler porque através da leitura adquiro mais conhecimento, são } \\
\text { histórias interessantes, gosto de romance e suspense." }\end{array}$ \\
\hline A9 & $\begin{array}{l}\text { "Acho que é porque a gente entende e também adquire conhecimento. Eu } \\
\text { não lia, mas uma amiga minha vivia lendo, perguntei o que tinha de bom... }\end{array}$ \\
\hline
\end{tabular}




\begin{tabular}{|c|l|}
\hline & $\begin{array}{l}\text { então comecei e não parei, antes minha mãe mandava eu ler e eu tinha } \\
\text { preguiça." } \\
\text { "Encaixo-me no personagem, imagino-me, vivo novas aventuras." }\end{array}$ \\
\hline A10 & "Gosto de ação, suspense, adolescente como personagem." \\
\hline A11 & "É um passatempo bom." \\
\hline
\end{tabular}

Fonte: A pesquisa.

Em E3 foram dadas as seguintes respostas, conforme o quadro 3:

Quadro 3 - Motivações para a leitura de best-sellers em E3

\begin{tabular}{|c|l|}
\hline Alunos da E2 & \multicolumn{1}{|c|}{ Motivações para a leitura de best-sellers } \\
\hline A1 & "A vontade de saber, a curiosidade, isso me beneficia de alguma forma." \\
\hline A2 & "Acho interessante, pesquiso ou pergunto se é bom.” \\
\hline A3 & $\begin{array}{l}\text { "A curiosidade de saber o que vai acontecer com o personagem central e } \\
\text { para passar o tempo.” }\end{array}$ \\
\hline A4 & "Procuro na internet, se eu gostar do conceito, então...” \\
\hline A5 & "Leio porque o título é interessante.” \\
\hline A6 & "Quando traz aventura, romance e suspense.” \\
\hline A7 & "Alguns amigos me indicam dizendo que é muito bom.” \\
\hline A8 & "Pela magia, ficção, fantasia, história que conta." \\
\hline A9 & "Os mistérios.” \\
\hline A10 & "A curiosidade e também porque acho bom e interessante.” \\
\hline
\end{tabular}

Fonte: A pesquisa

A totalidade das respostas revela que o fator preponderante para leitura dos best-sellers é o gosto. Temos uma implicação de prazer a partir dos textos lidos pelos participantes da pesquisa, talvez não a fruição definida por Roland Barthes (1987), mas os primeiros passos para se chegar a ela. A fruição é uma extensão das relações de prazer estabelecidas entre os leitores e suas leituras. Consiste em desafio, tira o sujeito leitor da zona de conforto através de novidades desconhecidas. Percebemos, então, que os best-sellers são essas relações de prazer em busca da fruição citada pelo autor.

Esses dados revelam um amplo universo de motivações pelas quais guiam-se diferentes sujeitos. $\mathrm{O}$ ato da leitura não corresponde exatamente aos mesmos propósitos do que nos leva a ler um livro, por essa razão, há uma diversa lista de leituras possíveis. Essa divergência motiva 
as mais diferentes leituras dos mais variados gêneros da literatura, como orienta a Base Nacional Comum Curricular (BRASIL, 2017), quando reafirma a necessidade de o educando entrar em contato com diferentes tipos de textos literários, inclusive os textos veiculados ao universo da internet e que fazem parte do universo dos alunos do $9^{\circ}$ ano do ensino fundamental.

Aguiar e Bordini (1988) demonstram uma preocupação quanto à leitura da literatura na escola, no sentido de ter se tornado uma prática cada vez mais escassa, ocasionando desinteresse por parte dos aprendizes em virtude de a abordagem da literatura não atender, no ambiente escolar, as motivações e aspirações dos alunos.

Relação de best-sellers conforme interesses de leitura

A respeito do tempo dedicado à leitura de best-sellers, local de leitura, os alunos responderam o que consta nos quadros 4,5 e 6 .

Quadro 4 - Tempo dedicado a leitura de best-sellers em E1

\begin{tabular}{|c|l|}
\hline Alunos da E1 & Tempo dedicado às obras de categoria best-sellers e locais de leitura \\
\hline $\begin{array}{l}\text { A1, A2, A3, } \\
\text { A4, A5 e A6 }\end{array}$ & $\begin{array}{l}\text { Período noturno para a realização de suas leituras. Inclusive, indicam suas } \\
\text { casas como local privilegiado para isso. }\end{array}$ \\
\hline A7 & "À tarde umas duas horas e na minha casa" \\
\hline A8 & $\begin{array}{l}\text { "Fim de semana inteira, me tranco no quarto e fico a tarde toda, minha mãe } \\
\text { me chama de louca. Indico para meus amigos quando acho bonita a } \\
\text { história." }\end{array}$ \\
\hline A9 & $\begin{array}{l}\text { "Pela manhã e no tempo livre, em casa. Indico para amigos da escola e fora } \\
\text { da escola. Se eu acho o livro bom, então acho que as pessoas também podem } \\
\text { gostar." } \\
\text { "Á tarde umas duas horas por dia na minha casa. Indico aos meus colegas } \\
\text { por achar bom e interessante." }\end{array}$ \\
\hline
\end{tabular}

Fonte: A pesquisa

Quadro 5 - Tempo dedicado a leitura de best-sellers em E2

\begin{tabular}{|c|l|}
\hline Alunos da E2 & Tempo dedicado às obras de categoria best-sellers e locais de leitura \\
\hline $\mathrm{A} 1, \mathrm{~A} 3, \mathrm{~A} 5$, & $\begin{array}{l}\text { À tarde é o horário que leem. No entanto, apresentaram respectivamente, } \\
\text { diferentes locais de leitura, por mais que o elemento casa se faça presente, } \\
\text { outros locais foram citados, como viagens, a escola e a biblioteca, o tempo } \\
\text { destinado varia entre duas a quatro horas diárias. }\end{array}$ \\
$\mathrm{A} 11, \mathrm{~A} 12, \mathrm{~A} 10$ & $\begin{array}{l}\text { "Leio à tarde e à noite duas ou três horas, minha mãe briga porque passo } \\
\text { muito tempo lendo. Leio na biblioteca e em casa." }\end{array}$ \\
\hline $\mathrm{A} 8$
\end{tabular}




\begin{tabular}{|l|l|}
\hline A9 & $\begin{array}{l}\text { "No tempo livre, passo umas } 2 \text { horas lendo, leio na escola e em casa. Os } \\
\text { professores não pedem leitura, antes lia só para fazer resumo, agora é só o } \\
\text { livro didático." }\end{array}$ \\
\hline
\end{tabular}

Fonte: A pesquisa

Quadro 6 - Tempo dedicado à leitura de best-sellers em E3

\begin{tabular}{|l|l|}
\hline Alunos da E3 & Tempo dedicado às obras de categoria best-sellers e locais de leitura \\
\hline $\mathrm{A} 1, \mathrm{~A} 4, \mathrm{~A} 7$, & $\begin{array}{l}\text { O horário que preferem para a realização de suas leituras é à tarte. A respeito } \\
\text { do local todos os participantes leem em casa e o tempo dedicado às leituras } \\
\text { varia em torno de vinte minutos a quatro horas. }\end{array}$ \\
\hline $\mathrm{A}$ 2, A3, A5 & $\begin{array}{l}\text { Optam pela leitura à noite. A respeito do local todos os participantes leem } \\
\text { em casa e o tempo dedicado às leituras varia em torno de vinte minutos a } \\
\text { quatro horas. }\end{array}$ \\
\hline A6, A8 & $\begin{array}{l}\text { Usam o tempo livre para leituras. A respeito do local todos os participantes } \\
\text { leem em casa e o tempo dedicado às leituras varia em torno de vinte minutos } \\
\text { a quatro horas. }\end{array}$ \\
\hline
\end{tabular}

Fonte: A pesquisa

Os alunos compreendem a leitura como ato vinculado a suas casas, visto que fica subentendido como ação de leitura o que está na base de suas preferências, algo que implica prazer, deleite, uma busca por iniciativa própria. Os horários citados são em sua maioria aqueles em que estão fora da escola. O turno manhã foi o menos citado o que implica o horário em que os alunos estão na escola.

Para Chartier (2012), é necessário que a leitura seja sempre uma prática que se incorpora a gestos, espaços e hábitos. Precisa distanciar-se da fenomenologia de leituras que apaguem as modalidades concretas do ato da leitura. Ler significa construir seus próprios hábitos, livre de imposições espaciais. É isso que distingue os leitores e o que se chama de tradição de leituras. Os contrastes devem ser considerados nos seus mais diferentes aspectos.

Os jovens leitores compreendem o ato da leitura como ação que demanda lugar e ações específicas, tendo suas razões definidas. A riqueza e apreço por essas leituras revela-se no tempo dedicado a elas, uma vez que esse ato não acontece apenas uma vez por semana, sendo algo contínuo e rotineiro, o que mostra uma consolidação do hábito leitor, alguns participantes chegam até a passar tardes inteiras lendo.

Quando citaram suas casas como espaços privilegiados para as leituras, os aprendizes revelaram, em maioria, o quarto como local cativo para realizá-las, preferem um lugar mais calmo e tranquilo, como se fossem apenas eles e os livros. Essa presença da leitura constante dos best-sellers contagia cada um dos alunos e impulsiona-os a comentarem com os amigos, a partilharem algo de que realmente gostam, esse gosto é motivador e interessante para eles. 
Sobre isso Zumthor (2000) corrobora as palavras de Chartier (2012) em que revela essa especificidade de lugar imbricado ao ato da leitura. Para ele, ler configura-se como uma reiterabilidade própria, visto que é hábito, e não se configura apenas como repetição de ação visual. Um conjunto de fatores somam-se: desde ações fisiológicas, psíquicas àquelas que dizem respeito ao ambiente e suas condições favoráveis para uma boa leitura. Esses fatores podem variar de leitor para leitor e também dependendo do tipo de leitura.

Com relação a E2, o período de leitura dessas obras costuma ser uma atividade quase que diária, os participantes revelaram que leem geralmente em suas casas, às vezes na escola, duas ou mais três horas por dia, geralmente no contraturno em que estudam à tarde e à noite, no tempo livre, inclusive final de semana. Diferente de E1, E2 pelo contato em que os alunos têm com os best-sellers na biblioteca da escola, apresentam esse espaço como local de leitura, pois a maior parte dos livros que leem são retirados da escola.

A quantidade de tempo que os alunos passam em E2, dedicando-se a essas leituras, é um fator bastante interessante, porque permite situarmos a intensidade do apreço que nutrem por elas. Nesse sentido, quando se debruçam sobre os livros, mergulham tão profundamente que parecem perder a noção de tempo, visto que, na fala dos participantes, não há demonstração de um cálculo exato acerca disso. Implica-se aqui o fator envolvimento, a concentração que corrobora a escolha do espaço para a leitura: o quarto. Revela-se uma relação de intimidade com o lido.

O tempo destinado às leituras, em E3, varia em torno de horários bem definidos: à tarde, à noite e no tempo livre em que dedicam umas duas horas de leituras. O local reservado para essas leituras é geralmente a casa. A1 e A2 diferenciam-se dos demais por mostrarem um apreço maior por essas leituras ao afirmarem que passam a tarde ou um dia inteiro lendo. Essas duas escolas apresentam traços bastante semelhantes com relação ao envolvimento com os livros, o mergulho e conquista.

Concepção de literatura pelos participantes

Indagados sobre a classificação ou enquadramento dos livros de categoria best-sellers serem considerados da Literatura, os alunos responderam o que consta no quadro 7, 8 e 9 .

Quadro 7 - Concepção de literatura pelos participantes de E1

\begin{tabular}{|l|l|}
\hline Alunos da E1 & Concepção de literatura \\
\hline A3, A4, A5, A6, & Consideram as obras lidas como literatura \\
A7, A10, A11 & \\
\hline
\end{tabular}




\begin{tabular}{|l|l|}
\hline A2 & Os best-sellers lidos não se enquadram na literatura \\
\hline A1 e A9 & $\begin{array}{l}\text { Acham que sim, mas afirmam que Cinquenta tons de cinza não faz parte } \\
\text { da literatura, e excluem também da lista de literários A culpa é das } \\
\text { estrelas e Harry Poter. }\end{array}$ \\
\hline
\end{tabular}

Fonte: A pesquisa

Sobre as considerações dos participantes em E2, percebemos que as respostas se dividiram de maneira bastante equilibrada entre certezas e incertezas.

Quadro 08 - Concepção de literatura pelos participantes de E2

\begin{tabular}{|c|l|}
\hline $\begin{array}{c}\text { Alunos da } \\
\text { E2 }\end{array}$ & \multicolumn{1}{c|}{ Concepções de Literatura } \\
\hline A3, A5, A6, & $\begin{array}{l}\text { Demonstram certeza ao responderem que são obras que se enquadram no } \\
\text { cânone e portanto, são literárias. Explicam que assim as consideram por } \\
\text { provocarem inspiração nos leitores. }\end{array}$ \\
\hline A9, A11 & $\begin{array}{l}\text { As incertezas de ao responderem com os termos "acho que sim" e não } \\
\text { explicarem o porquê da resposta. }\end{array}$ \\
A10, A12.
\end{tabular}

Sobre o enquadramento dos best-sellers como literatura, os participantes de E3 representaram uma certeza maior que as outras escolas.

Quadro 9 - Concepção de literatura pelos participantes de E3

\begin{tabular}{|c|l|}
\hline Alunos da E3 & \multicolumn{1}{|c|}{ Concepção de literatura } \\
\hline $\mathrm{A} 1, \mathrm{~A} 2, \mathrm{~A} 3, \mathrm{~A} 4$, & $\begin{array}{l}\text { Responderam categoricamente que sim, não souberam explicar as } \\
\mathrm{A} 5, \mathrm{~A} 6, \mathrm{~A} 7, \mathrm{~A} 10\end{array}$ \\
\hline $\mathrm{A} 9$ & $\begin{array}{l}\text { Respos de tal classificação. } \\
\text { incerteza que não apresenta-se em nenhum outro participante. }\end{array}$ \\
\hline $\mathrm{A} 8$ & $\begin{array}{l}\text { Classificou apenas Harry Potter e Diário de um banana, os demais } \\
\text { não. }\end{array}$ \\
\hline
\end{tabular}

Fonte: A pesquisa

É perceptível que a maioria dos alunos acredita que as obras lidas são literatura. Não se percebe a visão dicotômica que apresenta a crítica: literatura erudita/literatura popular. Apesar de demonstrarem essa certeza, não souberam explicar as razões desse enquadramento.

Em todas as escolas, ficou clara a instabilidade de explicações acerca das obras lidas serem consideradas literárias. A maior parte acredita que aquilo que leem é literatura, apenas não sabem explicar as razões segundo as quais podem enquadrá-las nessa classificação. A relação dos leitores com a literatura pressupõe um envolvimento com o lido, o que é elucidado 
por Candido ao afirmar que "o público dá realidade e sentido à obra, e sem ele o autor não se realiza, o público é fator de ligação entre o autor e sua própria obra”. (CANDIDO, 2006, p. 47).

$\mathrm{O}$ autor traça uma relação tripla que aproxima as vertentes envolvidas, em que a interação é elemento que leva a todos os outros. Essa instabilidade se deve ao fato de que, até os presentes dias, não temos um conceito fechado de literatura. Entre os grandes teóricos isso não se esclarece, para os alunos também é um terreno de conflito, embora, por sua idade e ano escolar, não estejam a par de teorias compartilham desse terreno conflitante. Isso é percebido nas palavras de Compagnon, quando sintetiza: "Retenhamos disso tudo o seguinte: literatura é uma inevitável petição de princípio. Literatura é literatura”. (COMPAGNON, 1999, p. 46).

\section{Considerações finais}

A literatura constitui-se de diferentes funções, dentre as quais destacam-se o prazer, a fruição, o conhecimento e o gosto. Consoante a isso, percebemos os best-sellers da cultura de massa como obras pertencentes ao contexto escolar e presentes na realidade de leitura de muitos estudantes. Cabe ressaltar que, diante disso, a escola precisa direcionar olhares para o aproveitamento dos best-sellers como leituras válidas e capazes de formar leitores críticos, a partir de um trabalho de valorização das experiências de leitura que já trazem os alunos para a escola, e daí partir à inserção do cânone.

A pesquisa revelou a presença dessas leituras na escola e, portanto, a necessidade da valorização delas. Percebemos um apreço pelos best-sellers da cultura de massa diretamente relacionado as relações de prazer e gosto. Os estudantes demonstram um sentimento de gratuidade por essas leituras com horários e razões bem definidas para fazê-las, compreendem esse ato como hábito e atribuem as suas leituras as mesmas funções que cumpre a literatura do cânone. Por essa razão a necessidade da escola não se fechar a esse novo perfil de leitores.

Esperamos com esse trabalho contribuir para os estudos da literatura fora cânone a fim de direcionar olhares às realidades contextuais da atualidade, compreendendo os leitores que temos para construir os que queremos.

\section{Referências}

AGUIAR, Vera T. de; BORDINI, Maria da Glória. Literatura: a formação do leitor (alternativas metodológicas). Porto Alegre: Mercado aberto, 1988 
BARTHES, Roland. O prazer do texto. Tradução: J. Guinsburg. São Paulo: Editora Perspectiva, 1987.

BLOOM, Harold. O cânone ocidental: os livros e a escola do tempo. Tradução: Marcos Santarrita. Rio de Janeiro: Objetiva, 2001.

BRASIL. Ministério da educação. Base Nacional Comum Curricular. Brasília, 2017.

CANDIDO, Antônio. Literatura e sociedade. 9. ed. Rio de Janeiro: Ouro sobre azul, 2006.

CHARTIER, Roger. Os desafios da escrita. Tradução: Fulvia M.L Moretto. São Paulo: UNESPI, 2002.

COMPAGNON, Antoine. O demônio da teoria: literatura e senso comum. Tradução: Cleonice Paes Barreto. Mourão. Belo Horizonte: UFMG, 1999.

COSSON, Rildo. Letramento literário: teoria e prática. 2. ed. São Paulo: Editora Contexto, 2015.

DUMONT, Ligia Maria Moreira. A opção pela literatura de massa: simples lazer ou alienação?. Revista Investigación bibliotecalógica. Minas Gerais, v. 14, n. 28, jan./jun. 2000.

FARIA, Vanessa F.S. O ensino de literatura e a formação do leitor literário: entre saberes, trajetórias de uma disciplina e suas relações com os documentos oficiais. Revista Iberoamericana de Educación, Mato Grosso, n. 49/7, p. 1-12, 2009.

FREIRE, José Antônio Torres. Os saberes da literatura e a formação do leitor. Revista Entreletras, Mato Grosso, n. 1, p. 191-208, 2010.

LIMA, L. S. Leitura de best-sellers: desafios à escola na formação do leitor. 2019. 192f. Dissertação (Mestrado Profissional em Letras) - Universidade Estadual do Piauí, Teresina, 2019.

LIMA, Sirleide de Almeida et al. O Best-seller e a formação do gosto pela leitura dos jovens leitores. Revista Eco Pós, Goiás, v. 18, n. 1, p. 190-204, 2015.

RIOLFI, Claudia et al. Ensino de Língua Portuguesa. São Paulo: Cengage Learning, 2014.

ROSSATO. Wilson. O que é um best-seller?. Revista de Letras. Brasília, ano 01, n. 11, abr. 1994.

SOARES, Magda. A escolarização da literatura infantil e juvenil. In: EVANGELISTA, Aracy Alves Martins; BRANDÃO, Heliana Maria Brina; MACHADO, Maria Zélia Versiani (organizadoras). Escolarização da leitura literária. 2. ed.. Belo Horizonte: Autêntica, 2011.

TODOROV, Tzvetan. A literatura em perigo. Tradução: Caio Meira. Rio de Janeiro: DIFEL, 2009.

ZUNTHOR, Paul. Performance, recepção e leitura. Tradução: Jerusa Pires Ferreira e Suely Fenerich. São Paulo: Cosac \& Naify, 2007. 
Revista ENTRELETRAS (Araguaína), v. 10, n. 2, jul/dez 2019 (ISSN 2179-3948 - online)

Recebido em 21 de julho de 2019. Aceito em 07 de outubro de 2019. 